\title{
The post-yield fracture of a ductile polymer film: Notch quality, essential work of fracture, crack tip opening displacement, and J-integral
}

A.B. Martínez

N. León

noel.leon@estudiant.upc.edu

D. Arencón

M. Sánchez-Soto

Centre Català del Plàstic, Departament de Ciència dels Materials i Enginyeria Metal-lúrgica, Universitat Politècnica de Catalunya-Barcelona TECH, C/Colom 114, 08222 Terrassa, Spain

${ }^{*}$ Corresponding author.

\section{Abstract}

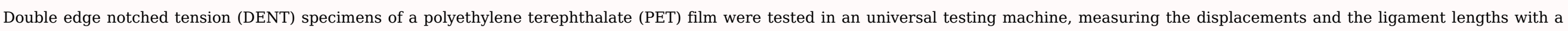

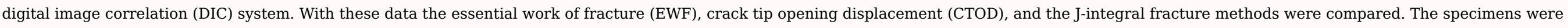

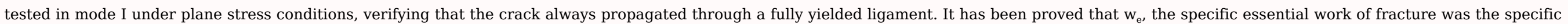

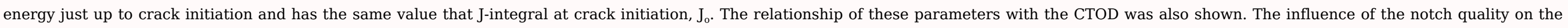
fracture behaviour when the specimens were sharpened by two different methods, femtosecond laser ablation or by razor blade sliding, has also been analysed in detail.

Keywords: Essential work of fracture; Crack tip opening displacement; J-integral; Polymer film; Femtolaser

\section{Nomenclature}

crack length

cte

constant

CTOD

crack tip opening displacement

displacement

DENT

double edge notched tension specimen

DIC

digital image correlation system 
elastic modulus

EPBC

ethylene-propylene block copolymer

EPFM

elastic plastic fracture mechanics approach

EWF

essential work of fracture approach

IPZ

inner process zone

$\mathrm{J}$

J-integral

LEFM

linear elastic fracture mechanics approach

OPZ

outer process zone

$\mathrm{P}$

load of tail curves extracted from load records

PET

polyethylene terephthalate

PYFM

post-yield fracture mechanics approach

$\mathrm{t}$

specimen thickness

$\mathrm{U}$

energy dissipated in fracture of the specimen

W

specimen width

Z 
geometrical shape factor related to the OPZ

v

poisson's ratio

$\mathrm{CTOD}_{\mathrm{c}}$

CTOD value at the onset of crack propagation

$\mathrm{d}_{\mathrm{i}}$

displacement at the onset of crack initiation $\mathrm{d}_{\mathrm{r}}$

displacement at specimen rupture

$l_{\mathrm{i}}$

ligament length measured during the test

$l_{o}$

initial ligament length

$l_{\text {we }}$

ligament length at $d_{i}$

Jo

J-integral value at crack initiation

$r_{p}$

plastic zone radius

$\mathrm{w}_{\mathrm{e}}$

specific work of fracture

$\mathrm{W}_{\mathrm{e}}$

essential work of fracture

$\mathrm{w}_{\mathrm{f}}$

specific total energy

$\mathrm{W}_{\mathrm{f}}$ 
$\mathrm{w}_{\mathrm{p}}$

specific non-essential work of fracture

$\mathrm{W}_{\mathrm{p}}$

plastic work or non-essential work of fracture

$\Delta \mathrm{a}_{\mathrm{b}}$

increment of crack length at blunting

$\sigma_{\mathrm{fs}}$

engineering flow stress

$\sigma_{\mathrm{i}}$

stress at the onset of crack initiation

$\sigma_{\mathrm{n}}$

nominal stress

$\sigma_{\mathrm{y}}$

uniaxial tensile yield stress

\section{Introduction}

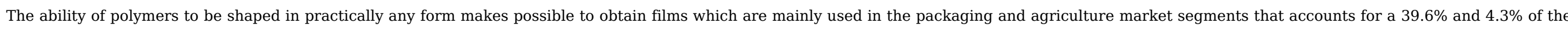
plastic global demand, respectively.

The classical tests for determining the mechanical properties of polymer films are well established and standardized, but this is not the case for the fracture properties.

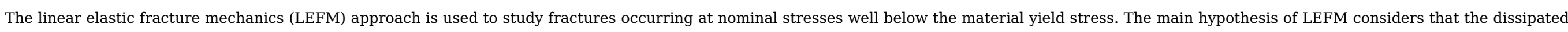
energy is confined in a small area near the crack tip (small scale yielding), and the fracture is brittle, without extensive deformation.

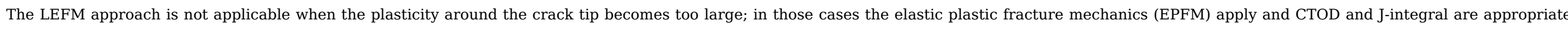

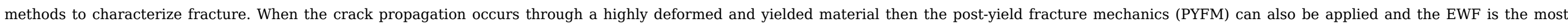
suitable method. For ductile polymers where crack propagation occurs through a fully yielded ligament, the EWF, the CTOD, and the J-integral are commonly used.

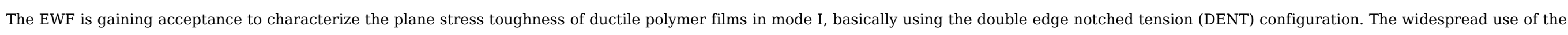
EWF technique is due to the apparent simple DENT specimen preparation and the simple testing.

The specific work of fracture, $\mathrm{w}_{\mathrm{e}}$, becomes an inherent material parameter only if the ligament fully yields before the crack initiation.

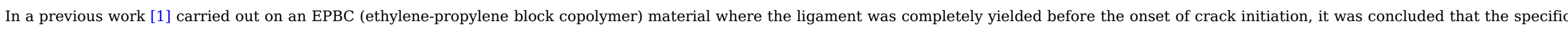

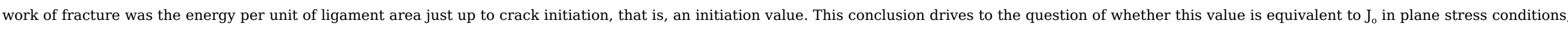

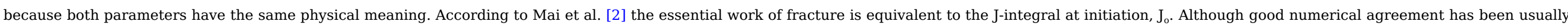

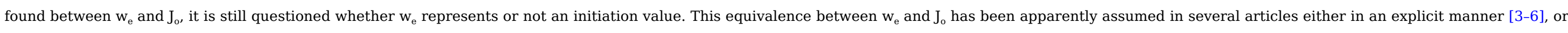
in an implicit way [7-12]. It should be mentioned that there is only one unique clear evidence that $\mathrm{w}_{\mathrm{e}}$ is an initiation value, as has been demonstrated in a previous work on an EPBC film [1]. 


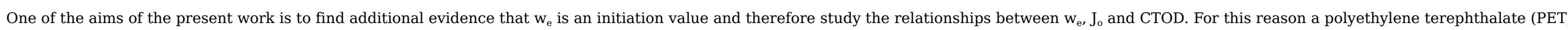

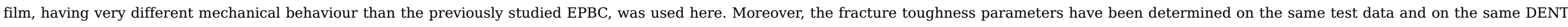
specimens.

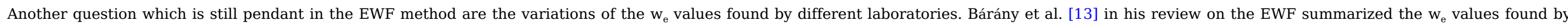

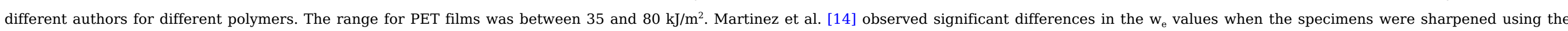

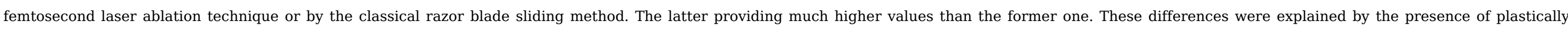

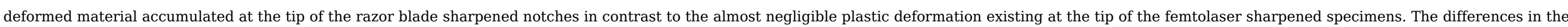
$\mathrm{w}_{\mathrm{e}}$ values were attributed to differences in the notch quality produced. Therefore another aim of this work is to investigate in detail the effect of the notch quality on the fracture behaviour.

\section{Background}

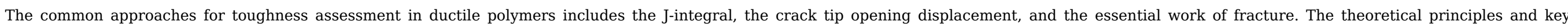
assumptions of these methods are summarized in the following sections.

\subsection{Essential work of fracture}

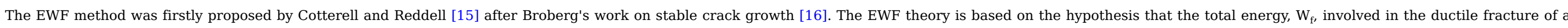
precracked specimen can be separated in two terms.

$\mathrm{W}_{\mathrm{f}}=\mathrm{W}_{\mathrm{e}}+\mathrm{W}_{\mathrm{p}}$

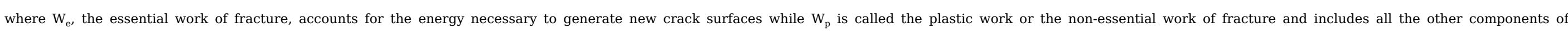
energy dissipated in the fracture process.

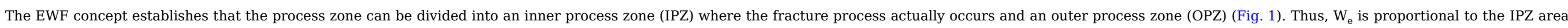
while $\mathrm{W}_{\mathrm{p}}$ is proportional to the volume of the OPZ. Using these considerations, Eq. (1) can be rewritten in specific terms as follows

$\mathrm{w}_{\mathrm{f}}=\frac{\mathrm{w}_{\mathrm{f}}}{1_{\mathrm{o}} \mathrm{t}}=\mathrm{w}_{\mathrm{e}}+\beta \mathrm{w}_{\mathrm{p}} \cdot \mathrm{l}_{\mathrm{o}}$

where $l_{o}$ is the ligament length, $t$ is the specimen thickness and $\beta$ is a factor related to the shape of the OPZ.

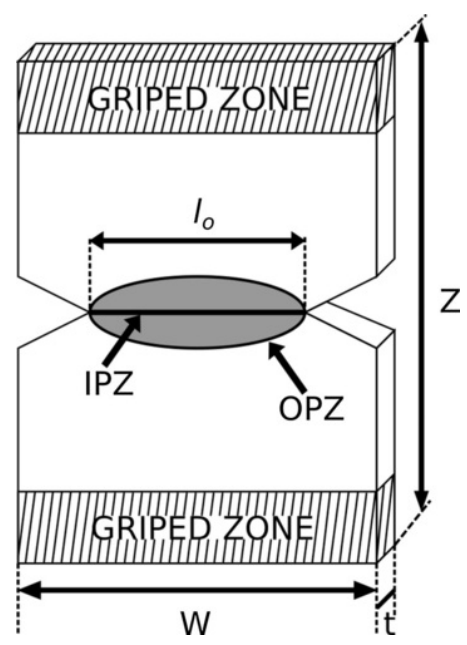




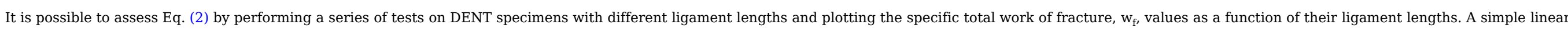

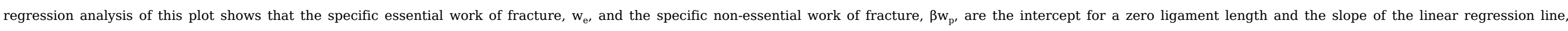
respectively. References [13,17] contain a detailed description of the EWF methodology.

In the EWF analysis the following key assumptions are taken:

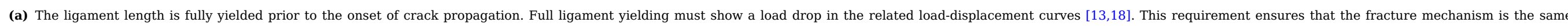

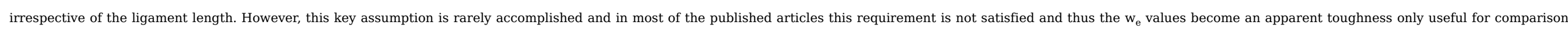
purposes.

Plane stress conditions and full ligament yielding prior to the crack initiation are accomplished if the following equation is fulfilled.

$1_{0}<2 r_{p}$

where $r_{p}$ is the plastic zone radius and can be obtained through:

$2 \mathrm{r}_{\mathrm{p}}=\frac{\pi}{8}\left(\frac{\mathrm{Ew}_{\mathrm{e}}}{\sigma_{\mathrm{y}}^{2}}\right)$ for a linear plastic zone

$2 r_{p}=\left(\frac{E w_{e}}{\pi \sigma_{y}^{2}}\right)$ for a circular plastic zone

where $\mathrm{E}$ is the elastic modulus, $\sigma_{\mathrm{y}}$ is the uniaxial tensile yield stress, and $\mathrm{w}_{\mathrm{e}}$ is the specific essential work of fracture.

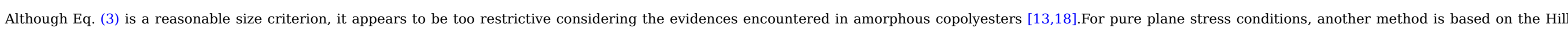
criterion [19-21] but does not ensure full ligament yielding.

(b) Fracture is under plane stress conditions.

In order to meet the plane stress conditions in the specimen ligament length it must be accomplished:

$1_{0} \geqslant 3 t$ or $5 t$

whereas the condition

$1_{\mathrm{o}} \leqslant \mathrm{W} / 3$

is necessary to prevent edge effects.

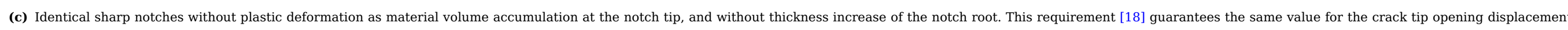
at initiation and results in the overlapping of the heads of the nominal stress-displacement and self-similar ligament length-displacement curves for the specimens having different ligament lengths.

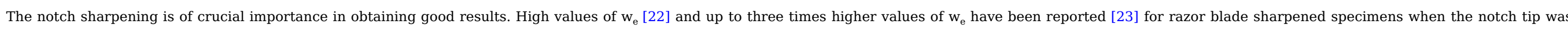

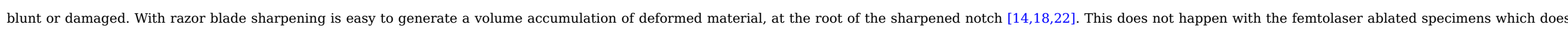

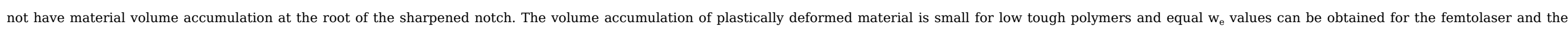

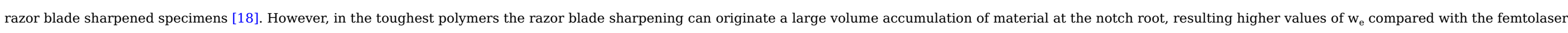
sharpened specimens [14].

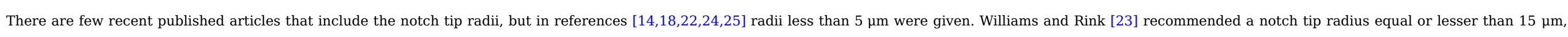




\subsection{The J-integral}

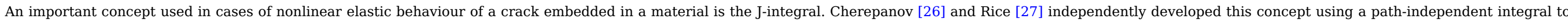
show a way to calculate the energy release rate per unit area of the crack surface that is created. In simple terms, the J-integral can be expressed as follows

$\mathrm{J}=-\frac{1}{t}\left(\frac{\mathrm{dU}}{\mathrm{da}}\right)_{\mathrm{d}=c t e}$

where $\mathrm{U}$ is the energy dissipated in the fracture of the specimen until a given constant displacement, $d$, and a is the crack length.

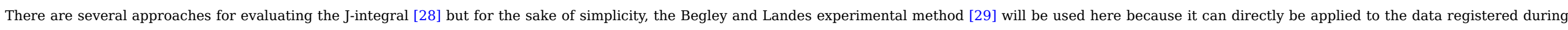
the testing of the DENT specimens.

\subsection{The crack tip opening displacement, CTOD}

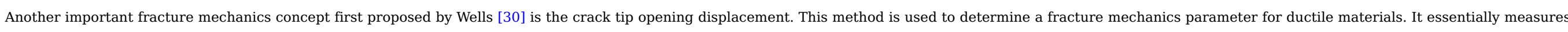
the resistance of a material to the propagation of a crack.

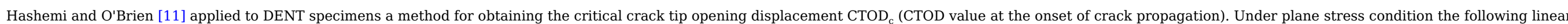
relationship exists

$\mathrm{d}_{\mathrm{r}}=\mathrm{CTOD}_{\mathrm{c}}+\alpha \cdot \mathrm{l}_{\mathrm{o}}$

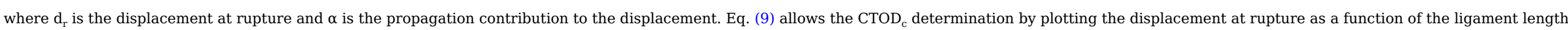

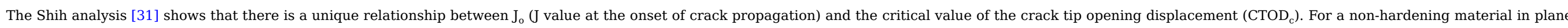
stress and assuming that the stress in the plastic zone is $\sigma_{\mathrm{y}}$ then

$\mathrm{J}_{0}=\sigma_{\mathrm{y}} \mathrm{CTOD}_{\mathrm{c}}$

\section{Material and specimen preparation}

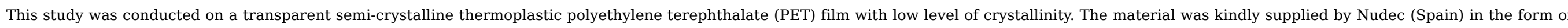
A4 sheets with a thickness of $0.5 \mathrm{~mm}$.PET is slightly hygroscopic and the sheets have the water absorption at saturation, $0.1-0.2 \%$.

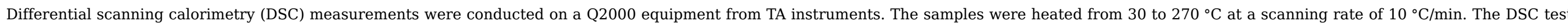

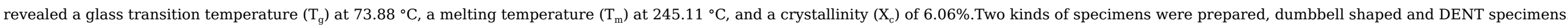

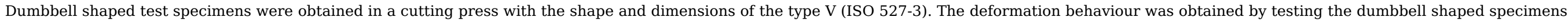
The Young's modulus, E, the uniaxial tensile yield stress, $\sigma_{y}$, and the Poisson's ratio, $v$, were determined according to the guidelines established in the ISO 527 standard.

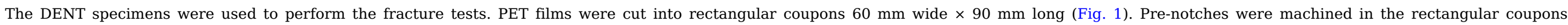

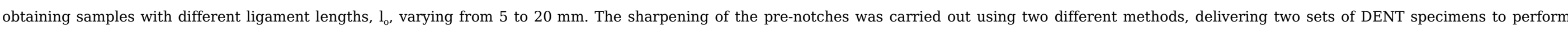
fracture testing.

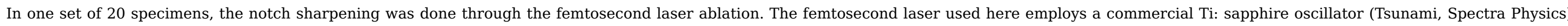

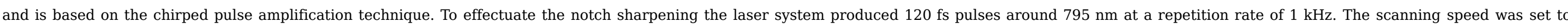
$130 \mu \mathrm{m} / \mathrm{s}$ with a pulse energy of $0.07 \mathrm{~mJ}$ and 8 passes of the laser beam.

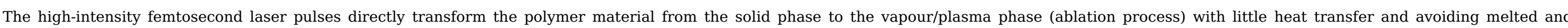




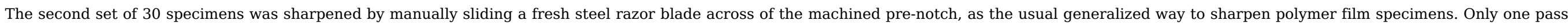
of the razor blade was applied in order to assure that the sharpened extension follow the same path. This technique was carried out manually by a highly skilled operator.

\section{Experimental details}

All tests were carried out in a Zwick servo-hydraulic testing machine fitted with a two camera digital image correlation (DIC) system (GOM, Germany).

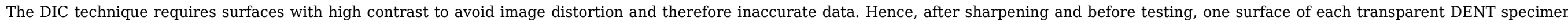

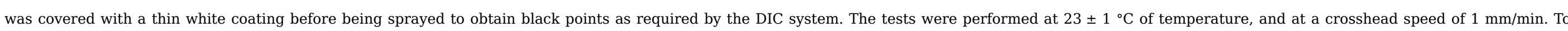
study the deformation behaviour, the strain was measured by the DIC system with the Aramis software (GOM, Germany).

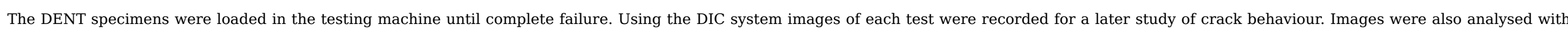

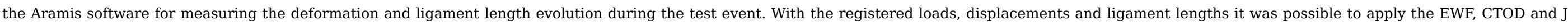
integral fracture techniques on the same specimens.

Two sets of data were registered, load as a function of displacement, and ligament length as a function of the displacement.

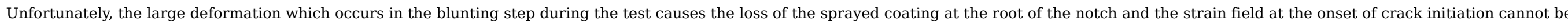
observed.

\section{Results and discussion}

\subsection{Deformation behaviour}

The uniaxial tensile yield stress $\left(\sigma_{\mathrm{y}}\right)$, modulus (E), and the Poisson's ratio $(\nu)$ of the PET material were measured on the dumbbell shaped specimens.

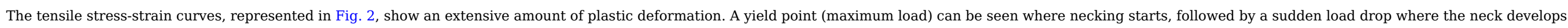
Afterwards, there is a drawing of the necked region (cold drawing) during which the tensile deformation continued at a constant stress level (engineering flow stress).

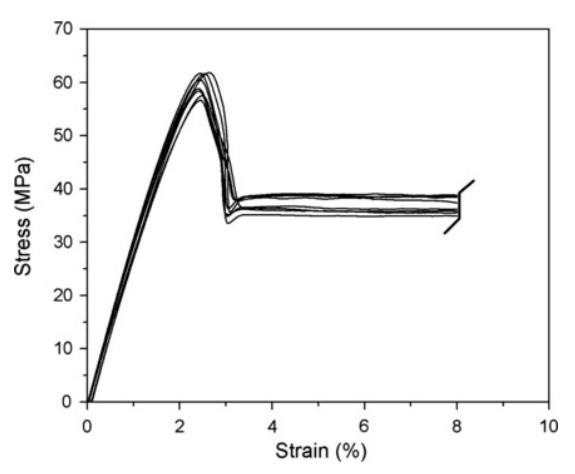

Fig. 2 Uniaxial stress-strain curves.

The results obtained from the tensile test are: $\mathrm{E}=2.64 \pm 0.02 \mathrm{GPa}, \sigma_{\mathrm{y}}=58.61 \pm 2.05 \mathrm{MPa}, \sigma_{\mathrm{fs}}$ (engineering flow stress) $=37.37 \pm 1.48 \mathrm{MPa}$, and $\nu=0.40 \pm 0.01$.

\subsection{Notch quality}

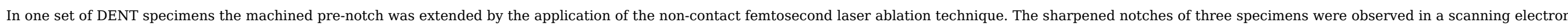




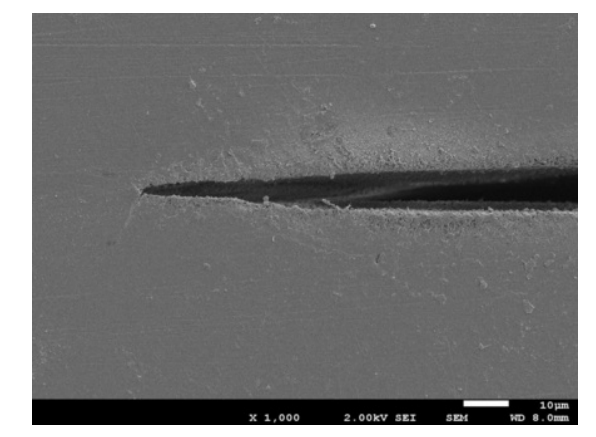

Fig. 3 SEM micrograph of femtolaser sharpened notch.

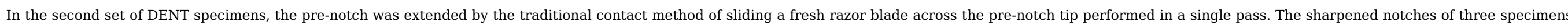

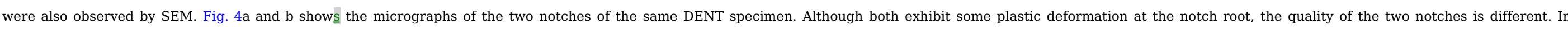

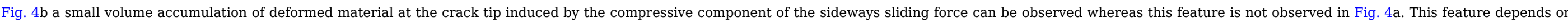

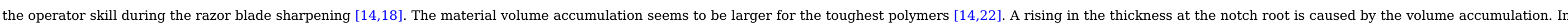

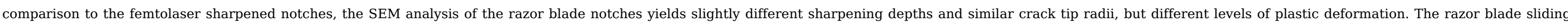
sharpening method generates notches of different quality which are strongly dependent on the operator skill.
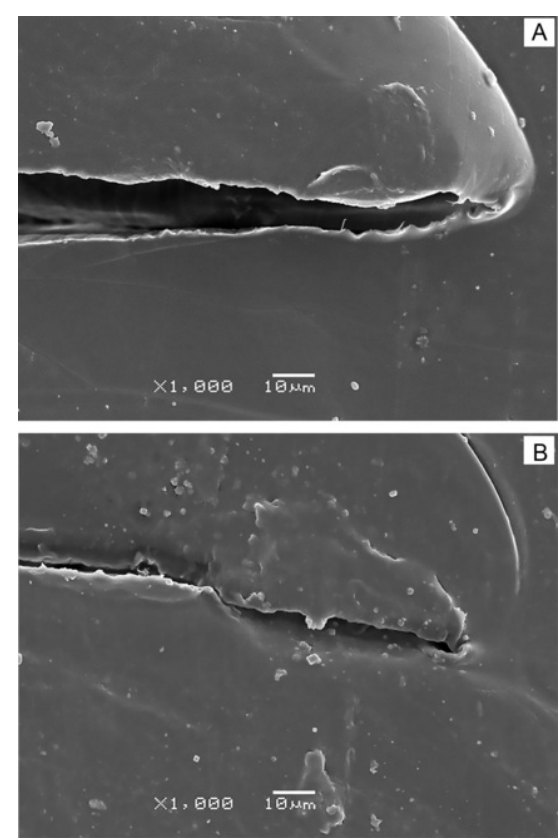

Fig. 4 SEM micrographs of razor blade sharpened notches: (a) Plastic deformation at the crack tip, (b) Plastic accumulation at the crack tip.

The SEM observations of the sharpened notches needed the destruction of the specimens and unfortunately they could not be tested. 


\subsection{DENT test}

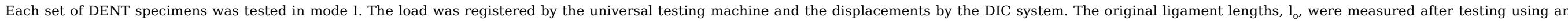

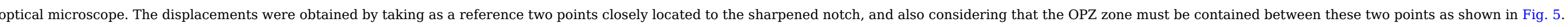

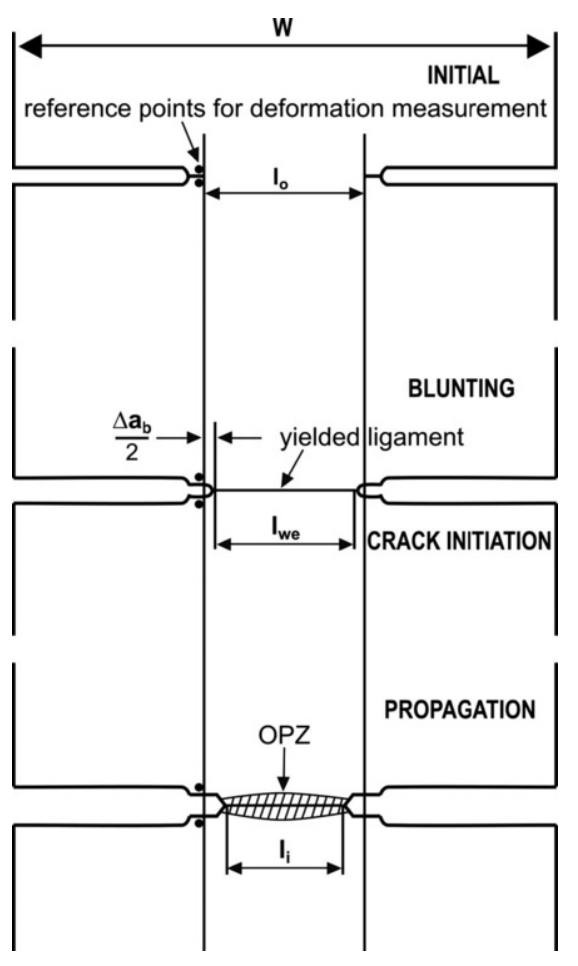

Fig. 5 Scheme of test evolution in a DENT specimen.

The load versus displacement curves are represented in Fig. 6a and b for the femtolaser and for the razor blade sharpened sets of specimens, respectively. 

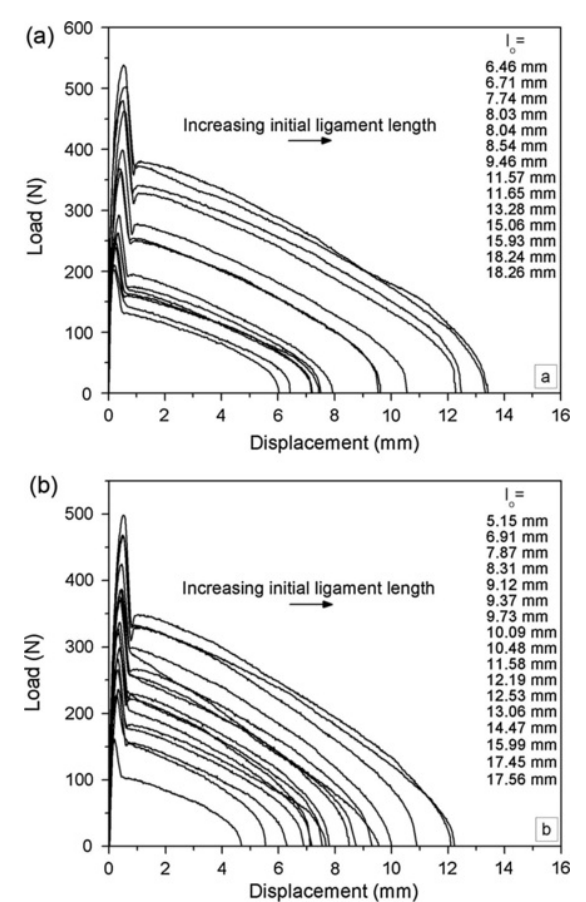

Fig. 6 Load-displacement data: (a) Femtolaser sharpened specimens, (b) Razor blade sharpened specimens.

The frames collected by the DIC system were also processed by the Aramis software and the obtained data of the ligament length as a function of the displacement are represented in Fig. $7 \mathrm{a}$ and $\mathrm{b}$. 

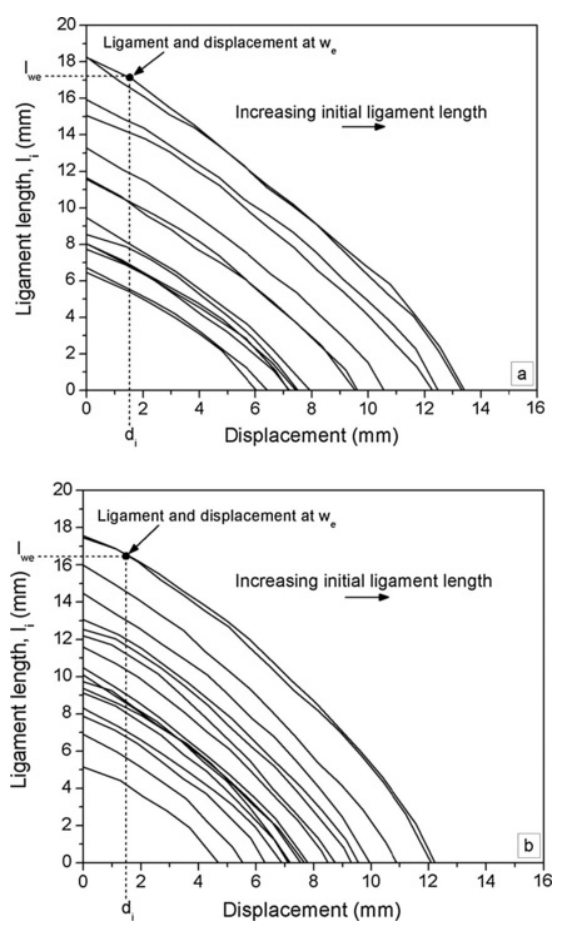

Fig. 7 Tracking of the ligament length during fracture testing: (a) Femtolaser sharpened specimens, (b) Razor blade sharpened specimens.

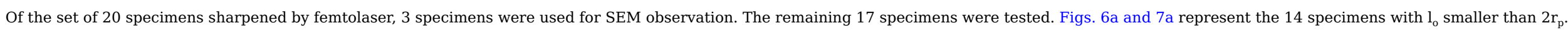

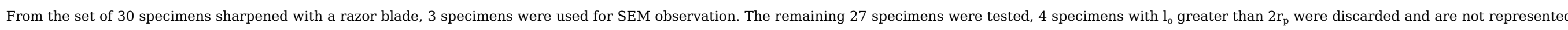
in Figs. $6 \mathrm{~b}$ and $7 \mathrm{~b}$. In these figures there are some slightly crossing curves, but we are not able to distinguish between them, these specimens showed the simultaneous crack propagation of both notches.

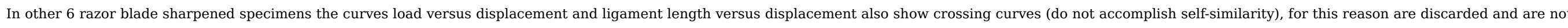

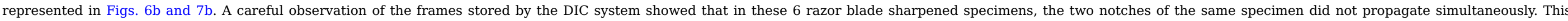

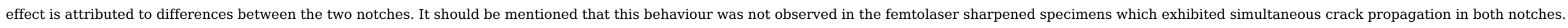

\subsection{Essential work of fracture}

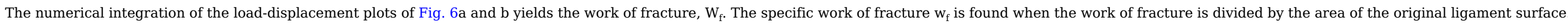

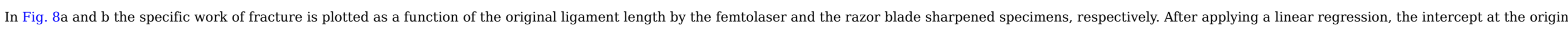
gives the $w_{e}$ value, being $\beta w_{p}$ the slope as indicated by Eq. (2). 

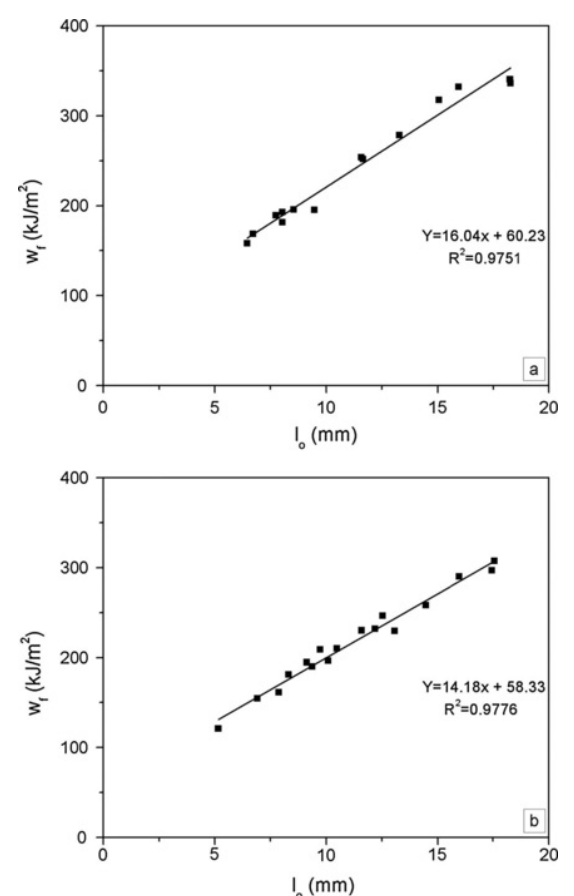

Fig. 8 Essential work of fracture plot: (a) Femtolaser sharpened specimens, (b) Razor blade sharpened specimens.

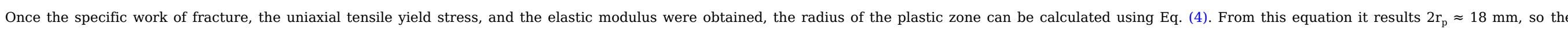

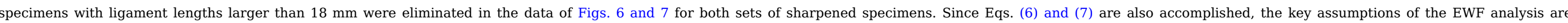

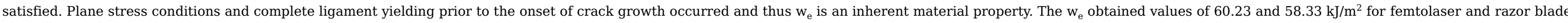

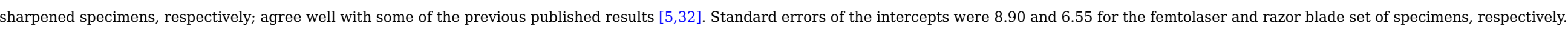

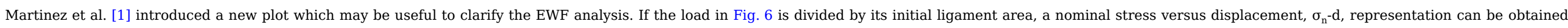

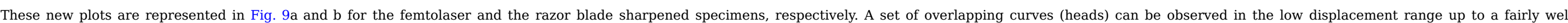

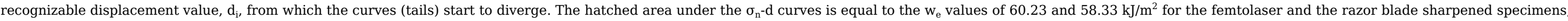

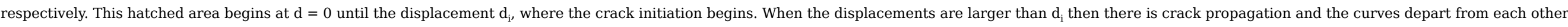



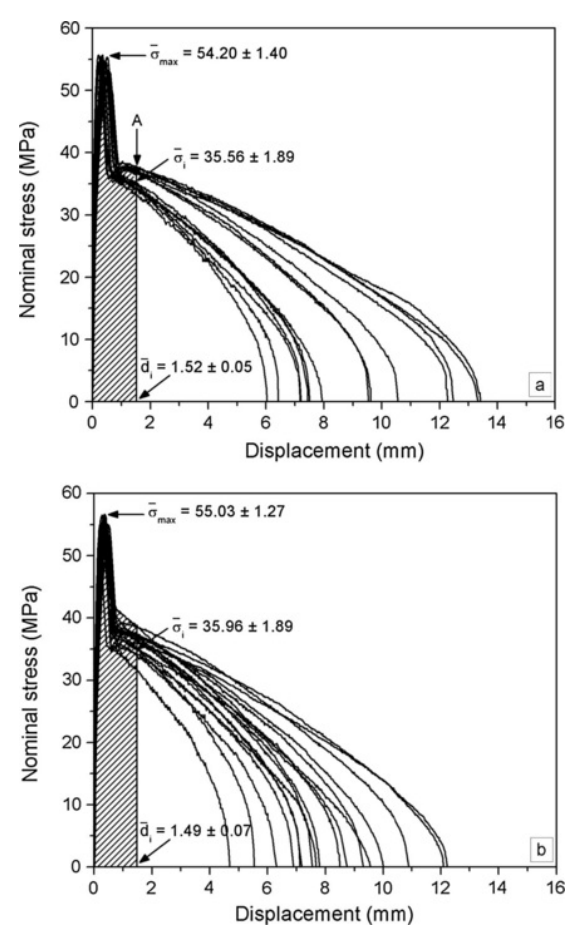

Fig. $9 \sigma_{n}-d$ curves: (a) Femtolaser sharpened specimens, (b) Razor blade sharpened specimens.

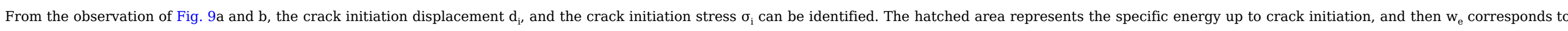

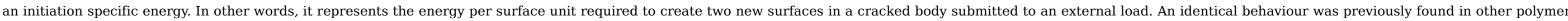
films $[1,18]$.

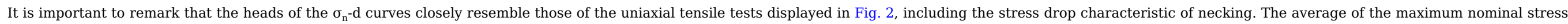
is basically equal to $\sigma_{\mathrm{y}}$ and $\sigma_{\mathrm{i}}$ is also almost equal to the engineering flow stress, $\sigma_{\mathrm{fs}}$.

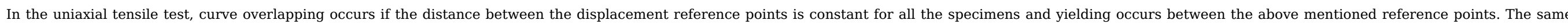
behaviour is observed for the heads in Fig. 9a and b.

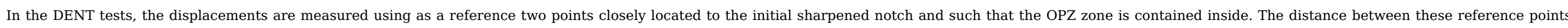

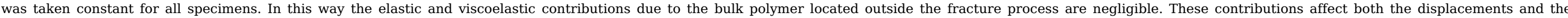

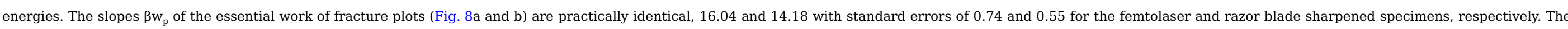
slopes do not depend of the notch sharpening method, as it has been found in other polymers [1,14,18], but the slope vary when the distance between the displacement reference points is changed [14].

A larger number of tested specimens can reduce the slope and intercept standard errors. More than 20 specimens have been recommended [23].

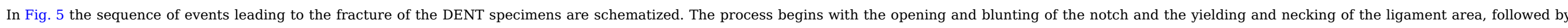
crack initiation and propagation until complete fracture. Prior to crack initiation onset there is an increment of the crack length $\Delta \mathrm{a}_{\mathrm{b}}$ due to blunting, being $\mathrm{l}_{\mathrm{we}}$ the remaining ligament length to be fractured.

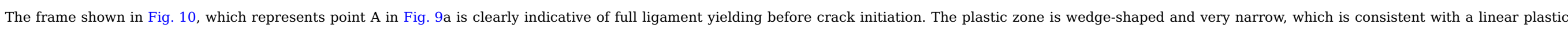
zone (Eq. (4)). These observations were similar in all valid specimens. 


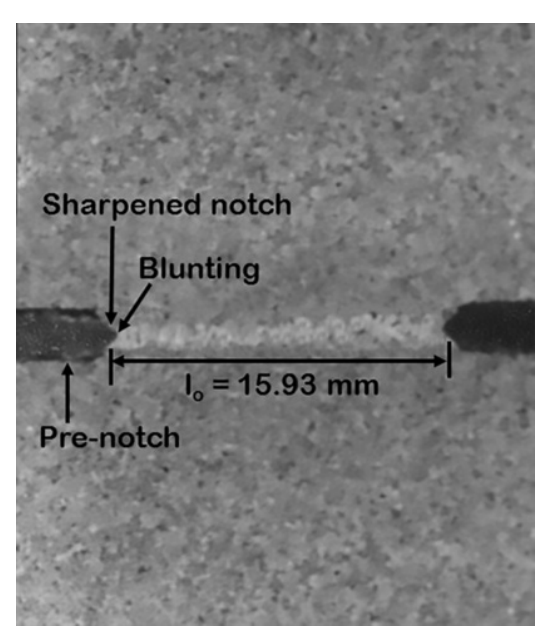

Fig. 10 Frame of a sprayed DENT accounting for the point A in Fig. 9a.

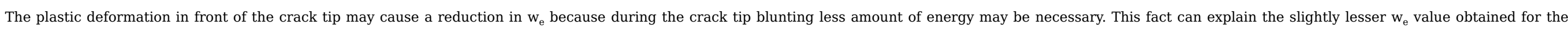

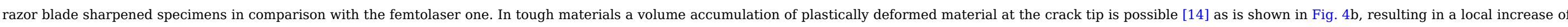

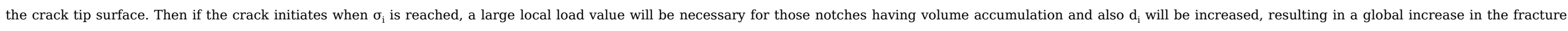

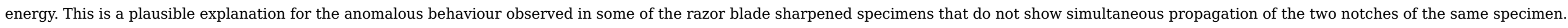

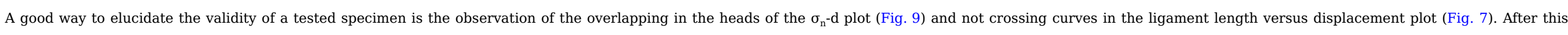
analysis, which eliminated the specimens with bad quality notches, the $\mathrm{w}_{\mathrm{e}}$ values for both sets of sharpened specimens were virtually identical.

The crack propagation can be analysed as well. When the ligament is completely yielded and necked then

$$
\mathrm{P}=\mathrm{t}(\mathrm{W}-\mathrm{a}) \sigma_{\mathrm{i}}
$$

where $\mathrm{P}$ is the load. The derivative yields

$\frac{\mathrm{dP}}{\mathrm{da}}=-\mathrm{t} \sigma_{\mathrm{i}}$

then a linear dependence of the load $\mathrm{P}$ with the crack length is predicted, being the slope equal to $-t \sigma_{i}$.

According to Fig. 5 the crack length is $\mathrm{a}=\mathrm{W}-\mathrm{l}_{\mathrm{i}}$

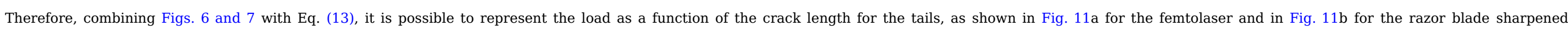

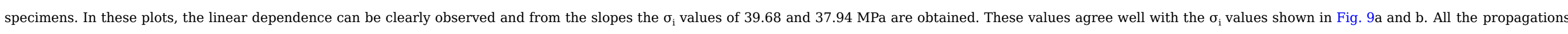

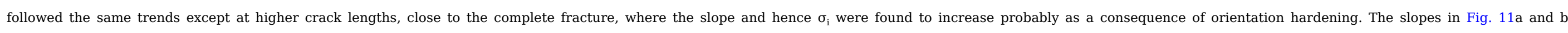

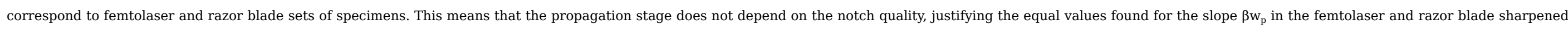
sets of specimens. 

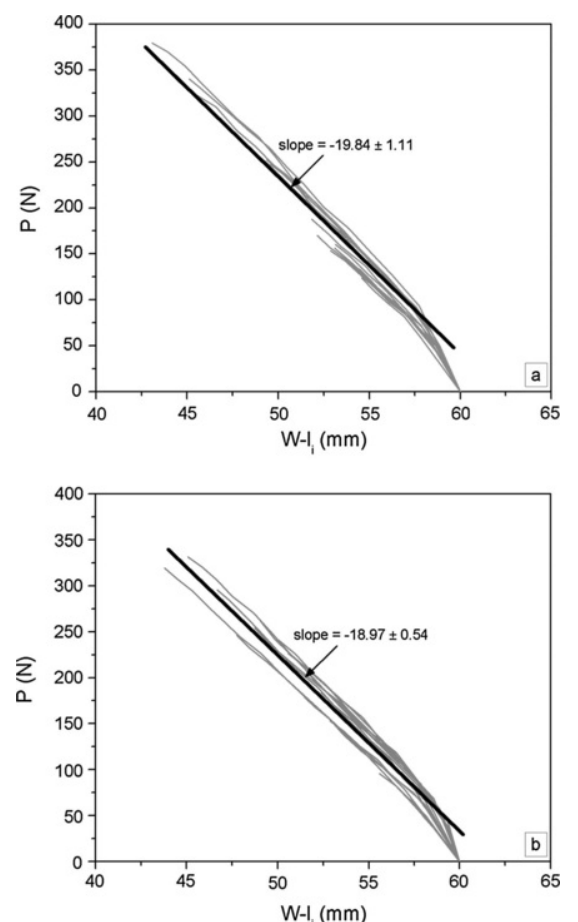

Fig. 11 Tails of load versus crack length: (a) Femtolaser sharpened specimens, (b) Razor blade sharpened specimens.

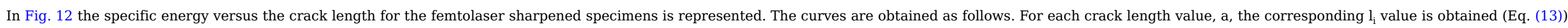

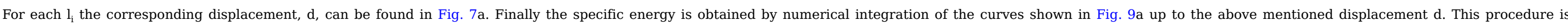
repeated for increasing a values and for each specimen.

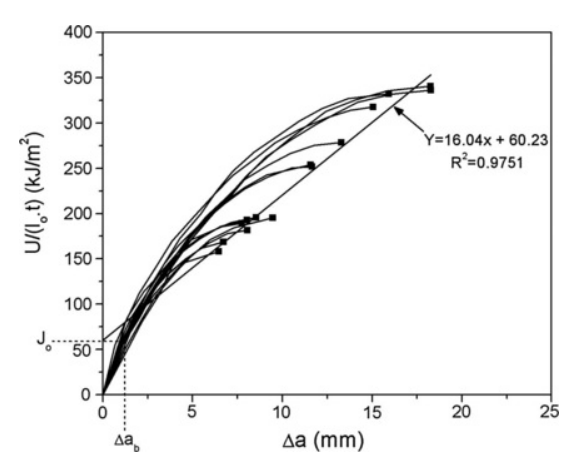

Fig. 12 Specific energy as a function of the crack length for femtolaser set of specimens.

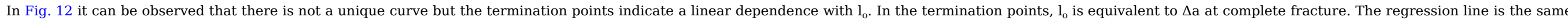
which was found in the EWF plot (Fig. 8a).

The crack length increment due to blunting just prior to crack initiation (Fig. 5) is given by 


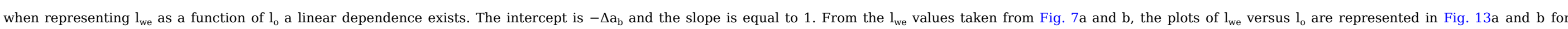
the femtolaser and the razor blade sharpened specimens, respectively. Both sets of specimens had a slope of 1 and the $\Delta \mathrm{a}_{\mathrm{b}}$ values were $1.15 \mathrm{and} 1.23 \mathrm{~mm}$.
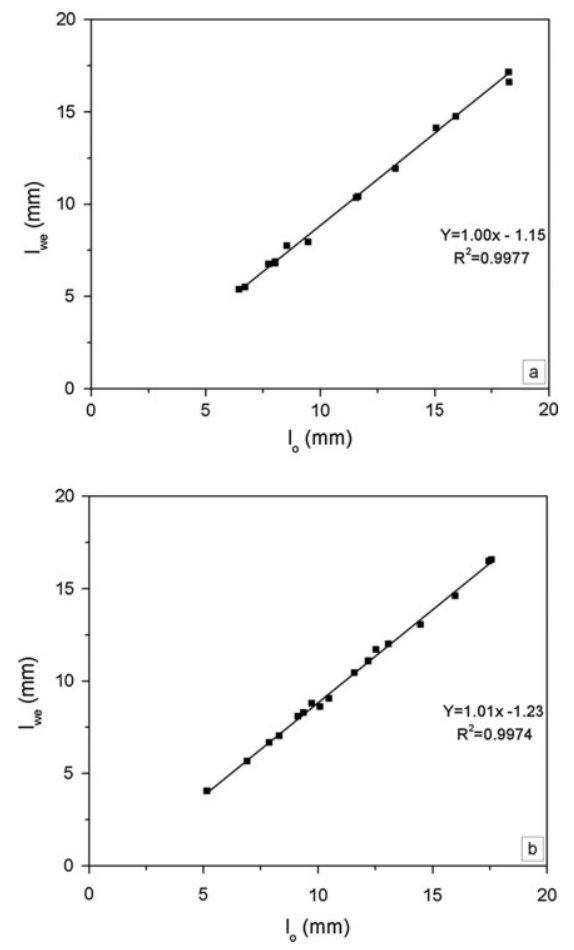

Fig. 13 Determination of the crack length at blunting: (a) Femtolaser sharpened specimens, (b) Razor blade sharpened specimens.

If the increment of crack length just prior to crack initiation $\Delta \mathrm{a}_{\mathrm{b}}$ is introduced in Fig. 12, a coincidence between the specific initiation energy and $\mathrm{w}_{\mathrm{e}}$ is again found.

\subsection{Crack tip opening displacement}

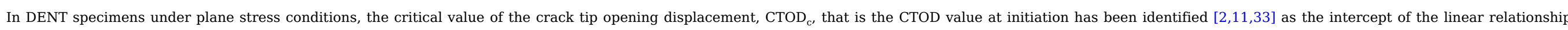
between the displacement at rupture, $d_{r}$, and the original ligament length $\mathrm{l}_{\mathrm{o}}$ (Eq. (9)).

Eq. (9) is only valid when there is no displacement contribution of the outside part of the OPZ zone.

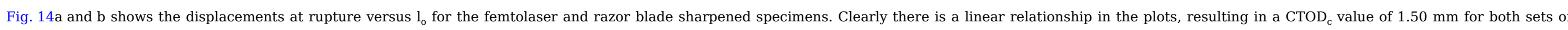
specimens, which as expected is coincident with the $d_{i}$ values shown in Fig. 9a and $b$. 

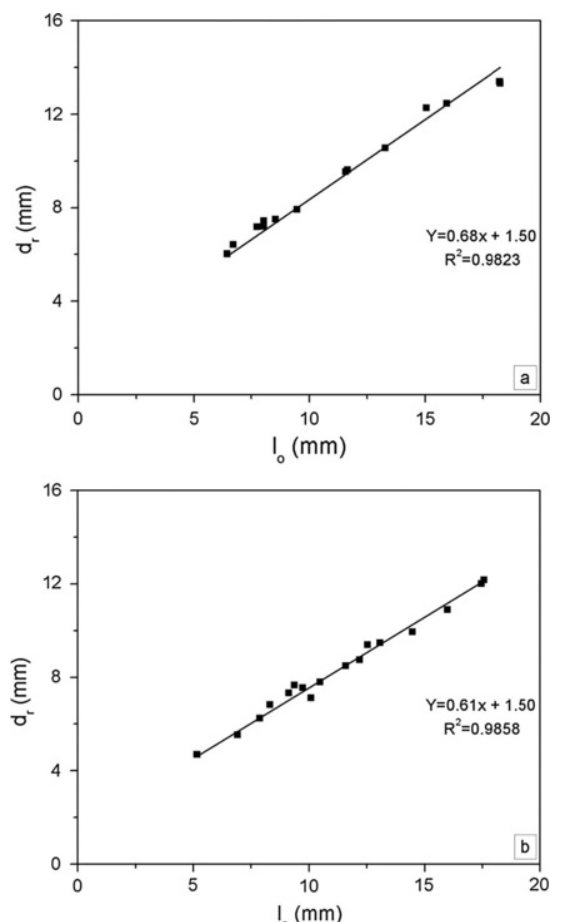

Fig. 14 Displacement at rupture versus $\mathrm{l}_{0}$ : (a) Femtolaser sharpened specimens, (b) Razor blade sharpened specimens.

\subsection{J-integral}

The Begley and Landes [29] method for the determination of the J-integral is based on Eq. (8) and requires graphical assessment of dU/tda at a constant displacement.

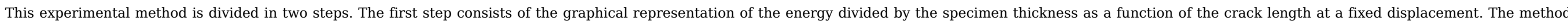

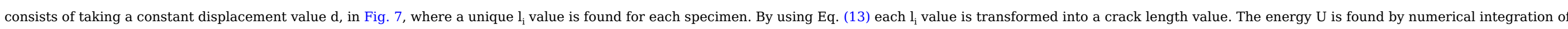

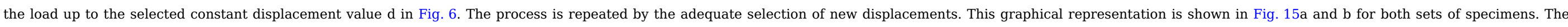
points belonging to the same displacement show linearity and can be fitted by a straight line. Following Eq. (8) the resultant slope from the regression line is -J. 

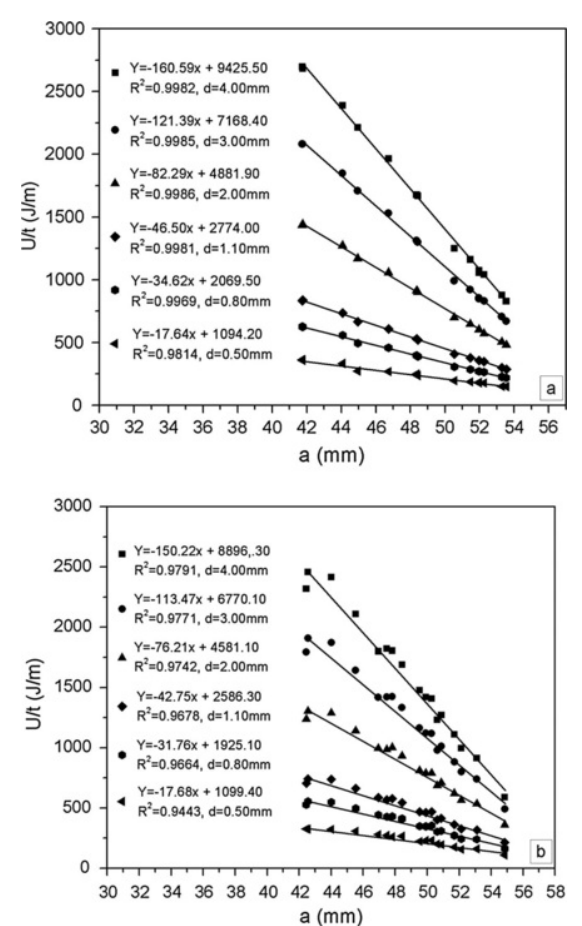

Fig. 15 Input energy divided by thickness versus crack length: (a) Femtolaser sharpened specimens, (b) Razor blade sharpened specimens.

The second step consists of the representation of the $J$ values versus displacement as illustrated in Fig. 16a and b for both set of specimens. 

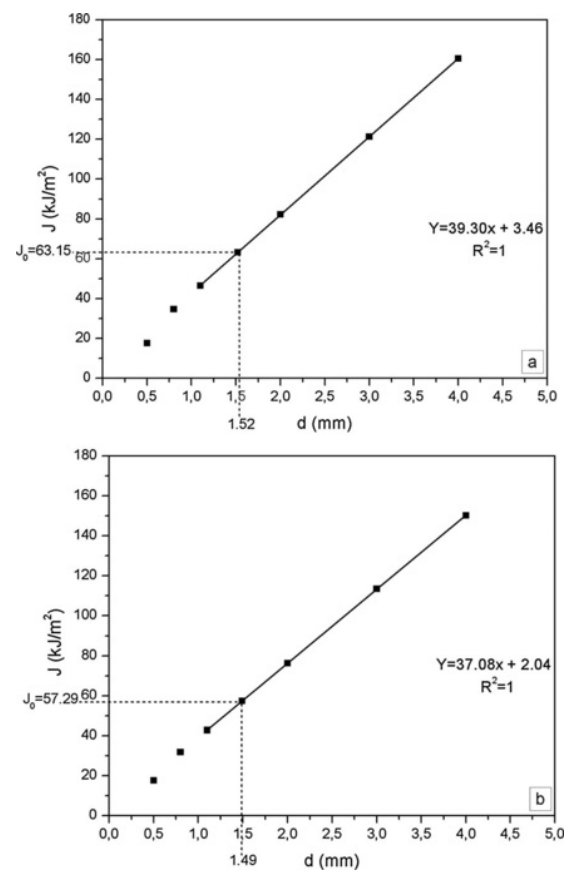

Fig. 16 J-integral: (a) Femtolaser sharpened specimens, (b) Razor blade sharpened specimens.

Following Hodgkinson and Williams [34], the total energy U for a non-work hardening full yielding of the ligament is $\mathrm{U}=\mathrm{P} . \mathrm{d}$

which combined with Eq. (11) results in

$\mathrm{U}=\mathrm{t}(\mathrm{W}-\mathrm{a}) \sigma_{i} \cdot \mathrm{d}$

$\mathrm{U} / \mathrm{t}$ is thus a linear function with the crack length at a constant fixed displacement, and is verified in Fig. 15a and b.

If Eq. (8) is combined with Eq. (16) the following expression is obtained

$$
\mathrm{J}=-\frac{1}{\mathrm{t}}\left(\frac{\mathrm{dU}}{\mathrm{da}}\right)_{\mathrm{d}=\mathrm{cte}}=\sigma_{i} \cdot \mathrm{d}
$$

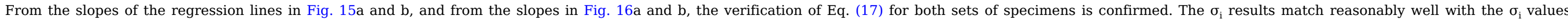
obtained before, taking into account the experimental variability and the involved large data treatment.

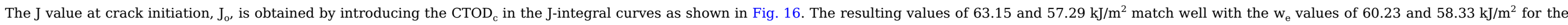
femtolaser and razor blade sharpened specimens, respectively.

Eq. (10) shows the relationship between $\mathrm{J}_{\mathrm{o}}$ and $\mathrm{CTOD}_{\mathrm{c}}$. In a completely yielded and necked material the stress in the plastic zone is $\sigma_{\mathrm{i}}$, then Eq. (10) should be modified as follows $\mathrm{J}_{\mathrm{o}}=\sigma_{i} \cdot \mathrm{CTOD}_{c}$

In the present study this relationship is completely fulfilled. Moreover, our analysis shows a complete relation between $\mathrm{w}_{\mathrm{e}}, \mathrm{J}_{0}$, and $\mathrm{CTOD}_{\mathrm{c}}$.

\section{Conclusions}




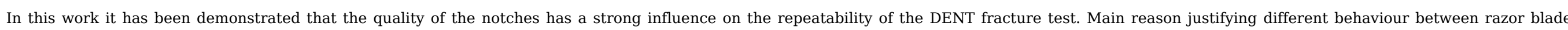

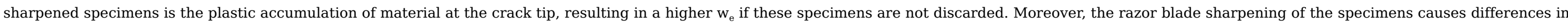

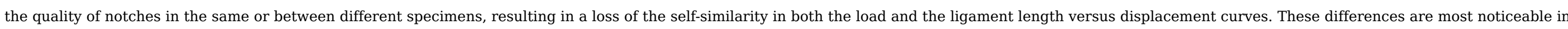

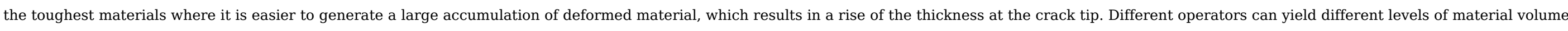

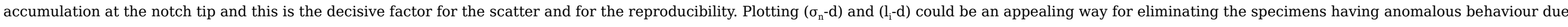
to their poor notch quality.

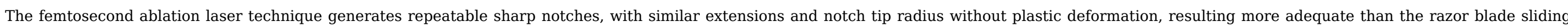
technique, especially for the fracture study of the toughest polymer films.

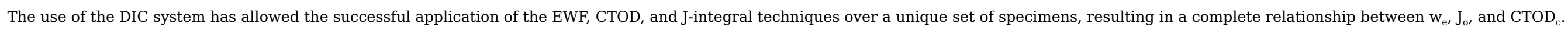

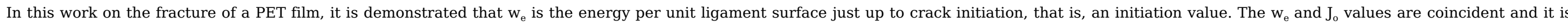

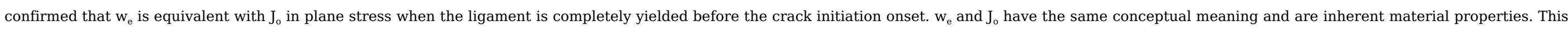
is not the case for materials where the ligament is not completely yielded before the crack initiation onset.

\section{Acknowledgements}

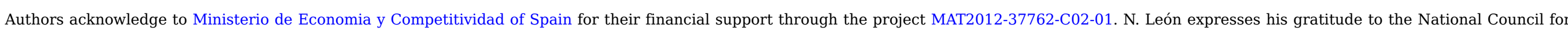
Science and Technology (CONACYT) based in Mexico for the doctoral fellowship.

\section{References}

[1] A.B. Martínez, A. Segovia, J. Gamez-Perez and M.L. Maspoch, Essential work of fracture analysis of the tearing of a ductile polymer film, Eng Fract Mech 77, $2010,2654-2661$.

[2] Y.W. Mai and P. Powell, Essential work of fracture and j-integral measurements for ductile polymers, J Polym Sci B Polym Phys 29, 1991, 785-793.

[3] Y.W. Mai and B. Cotterell, On the essential work of ductile fracture in polymers, Int J Fract 32, 1986, 105-125.

[4] G. Levita, L. Parisi, A. Marchetti and L. Bartolommei, Effects of thickness on the specific essential work of fracture of rigid PVC, Polym Eng Sci 36, 1996, $2534-2541$.

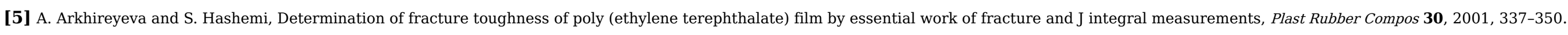

[6] A. Arkhireyeva and S. Hashemi, Fracture behaviour of polyethylene naphthalate (PEN), Polymer 43, 2002, 289-300.

[7] A. Arkhireyeva and S. Hashemi, Combined effect of temperature and thickness on work of fracture parameters of unplasticized PVC film, Polym Eng Sci 42, 2002 , 504-518.

[8] G. Levita, L. Parisi and S. Mcloughlin, Essential work of fracture in polymer films, J Mater Sci 31, 1996, 1545-1553.

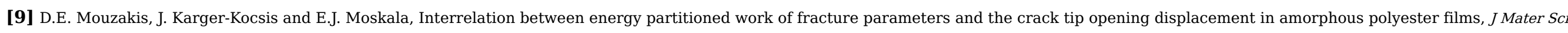
Lett 19, 2000, 1615-1619.

[10] J. Karger-Kocsis and T. Czigány, Strain-rate dependence of the work of fracture response of an amorphous poly (ethylene - naphthalate) (PEN) film, Polym Eng Sci 40, 2000, 1809-1815.

[11] S. Hashemi and D. O'Brien, The essential work of plane-stress ductile fracture of poly (ether - ether ketone) thermoplastic, J Mater Sci 28, 1993, $3977-3982$.

[12] A. Arkhireyeva and S. Hashemi, Effect of temperature on fracture properties of an amorphous poly (ethylene terephthalate) (PET) film, J Mater Sci 37, 2002, 3675-3683.

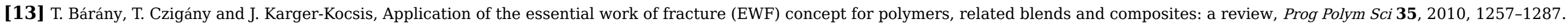

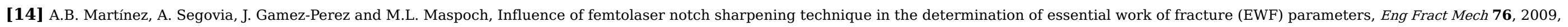


1247-1254.

[15] B. Cotterell and J.K. Reddel, The essential work of plane stress ductile fracture, Int J Fract 13, 1977, 267-277.

[16] K.B. Broberg, On stable crack growth, J Mech Phys Solids 23, 1975, 215-237.

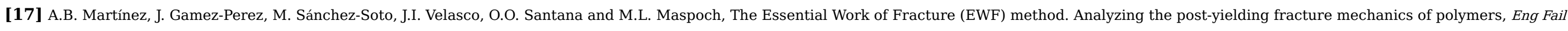
Anal 16, 2009, 2604-2617.

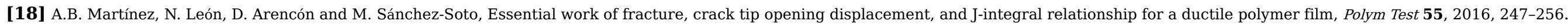

[19] R. Hill, On discontinuous plastic states with special reference to localized necking in thin sheets, J Mech Phys Solids 1, 1952, 19-30.

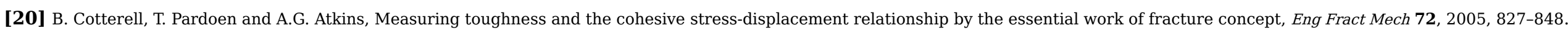

[21] F. Tuba, L. Oláh and P. Nagy, On the valid ligament range of specimens for the essential work of fracture method: the inconsequence of stress criteria, Eng Fract Mech 99, $2013,349-355$.

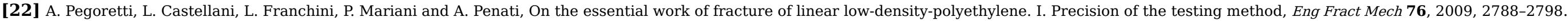

[23] J.G. Williams and M. Rink, The standardisation of the EWF test, Eng Fract Mech 74, 2007, 1009-1017.

[24] M. Rink, L. Andena and C. Marano, The essential work of fracture in relation to J-integral, Eng Fract Mech 127, $2014,46-55$.

[25] A. Dorigato and A. Pegoretti, Fracture behaviour of linear low density polyethylene-fumed silica nanocomposites, Eng Fract Mech 79, $2012,213-224$.

[26] G.P. Cherepanov, Crack propagation in continuous media, J Appl Math Mech 31, 1967, 476-488.

[27] J.R. Rice, A path independent integral and the approximate analysis of strain concentration by notches and cracks, J Appl Mech 35, 1968, 379-386.

[28] X.K. Zhu and J.A. Joyce, Review of fracture toughness (G, K, J, CTOD, CTOA) testing and standardization, Eng Fract Mech 85, $2012,1-46$.

[29] J.A. Begley and J.D. Landes, The J integral as a fracture criterion. In: Fracture toughness, ASTM STP 514, 1972, American Society for Testing and Materials; Philadelphia, 1-20.

[30] A.A. Wells, Application of fracture mechanics at and beyond general yielding, Br Weld J 10, 1963, 293-306.

[31] C.F. Shih, Relationships between the J-integral and the crack opening displacement for stationary and extending cracks, J Mech Phys Solids 29, 1981, 305-326.

[32] A. Arkhireyeva and S. Hashemi, Influence of temperature on plane stress ductile fracture of poly (ethylene terephthalate) film, Plast Rubber Compos 30, 2001 , 125-131.

[33] S. Hashemi, Fracture toughness evaluation of ductile polymeric films, J Mater Sci 32, 1997, 1563-1573.

[34] J.M. Hodgkinson and J.G. Williams, $J$ and $\mathrm{G}_{\mathrm{c}}$ analysis of the tearing of a highly ductile polymer, J Mater SCi 16, 1981, 50-56.

\section{Highlights}

- The notch quality affects the repeatability and reproducibility of the DENT test.

- The femtolaser is the best method for the notch sharpening of polymer films.

- $\mathrm{w}_{\mathrm{e}}$ is the specific energy just up to crack initiation.

- It is confirmed the equivalence between $\mathrm{J}_{\mathrm{o}}$ and $\mathrm{w}_{\mathrm{e}}$. 